http://jmscr.igmpublication.org/home/

ISSN (e)-2347-176x ISSN (p) 2455-0450

crossref DOI: https://dx.doi.org/10.18535/jmscr/v7i12.133

Journal Of Medical Science And Clinical Research

\title{
Leiomyosarcoma of Urinary Bladder - a case report and review of the literature
}

\author{
Authors \\ Lekha Madhavan Nair MD, DNB ${ }^{1}$, Hridaya Nelliparambath Haresh MBBS ${ }^{2}$, \\ Siva Ranjith J MS, Mch $^{3^{*}}$, Preethi T R MD ${ }^{4}$, Francis V James MD $^{5}$ \\ ${ }^{1}$ Senior Resident, Department of Radiation Oncology, Regional Cancer Centre, Trivandrum \\ ${ }^{2}$ Junior Resident, Department of Radiation Oncology, Regional Cancer Centre, Trivandrum \\ ${ }^{3}$ Assistant Professor, Department of Surgical Oncology, Regional Cancer Centre, Trivandrum \\ ${ }^{4}$ Additional Professor, Department of Pathology, Regional Cancer Centre, Trivandrum \\ ${ }^{5}$ Professor, Department of Radiation Oncology, Regional Cancer Centre, Trivandrum \\ *Corresponding Author \\ Dr Siva Ranjith J \\ Assistant Professor, Department of Surgical Oncology, Regional Cancer Centre, Trivandrum
}

\begin{abstract}
Leiomyosarcoma is a rare mesenchymal neoplasm arising from urinary bladder. Surgery is the mainstay of treatment. There is no consensus regarding adjuvant treatment. A 45 year old lady was evaluated for hematuria and cystoscopy showed a solid tumor arising from base of the urinary bladder. She underwent transurethral resection of bladder tumor and was referred to us with a histopathology report of leiomyosarcoma. She underwent radical cystectomy with ileal conduit and received adjuvant chemotherapy in view of high grade histology.

Keywords: Leiomyosarcoma, Urinary Bladder, cystectomy.
\end{abstract}

\section{Introduction}

Non urothelialtumors forms less than $5 \%$ of bladder malignancies. ${ }^{1} \quad$ Among them leiomyosarcoma (LMS) represents $0.1 \%$ of all bladder cancers. ${ }^{2}$ There are no standard treatment recommendations due to the rarity of the disease. Surgery is the mainstay of treatment. Here we present a case of LMS of urinary bladder treated with radical surgery and adjuvant chemotherapy.

\section{Case report}

A 45 year old post menopausal lady without any co-morbidities presented with hematuria of one month duration. Clinical examination did not reveal any significant findings. Cystoscopy showed $5 \times 5 \mathrm{~cm}$ solid growth arising from the base of the urinary bladder, abutting left ureteric orifice. She was further evaluated with CT abdomen and pelvis which showed soft tissue density lesion $5.8 \times 4.4 \mathrm{~cm}$ arising from the base of urinary bladder (figure 1). Transurethral resection of bladder tumor was done elsewhere and she was referred to us with a histopathology report of leiomyosarcoma bladder. Slide review at our centre confirmed the diagnosis of leiomyosarcoma (figure 2). Tumor cells were positive for SMA and 
desmin and MIB 1 index was 40-45\% (figure 3). After metastatic work up, she underwent anterior exenteration with enbloc cystectomy, Total abdominal hysterectomy +Bilateral Salpingo Oopherectomy and ileal conduit. Histopathology report showed no residual neoplasm and she received adjuvant chemotherapy with six cycles of Adriamycin and ifosfamide. The patient is now one year post treatment and is on regular follow up with no evidence of disease.

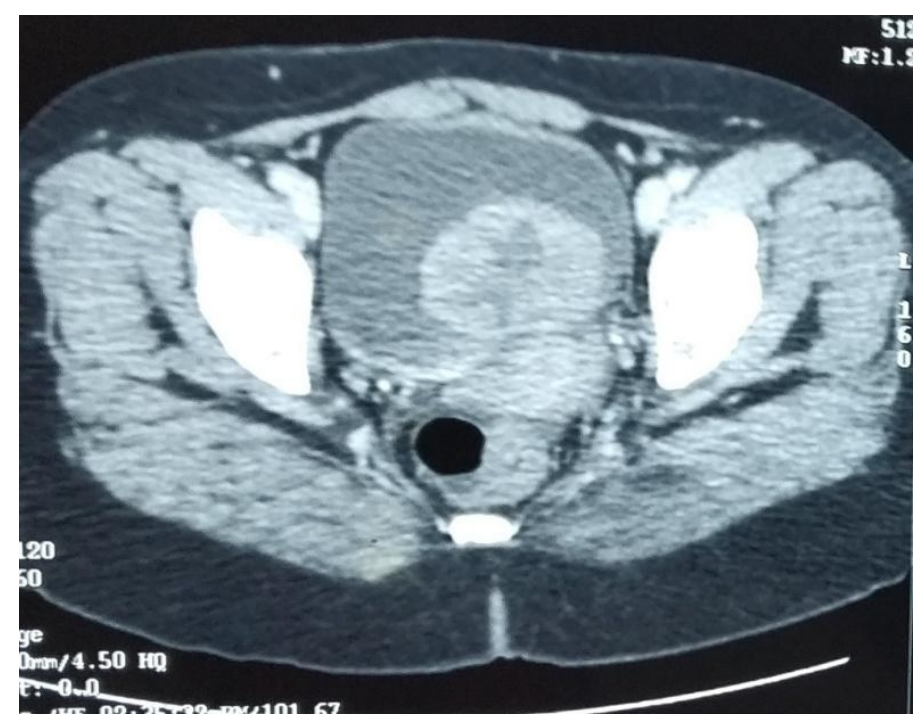

Figure 1: CT scan showing contrast enhancing soft tissue density lesion arising from the base of the urinary bladder

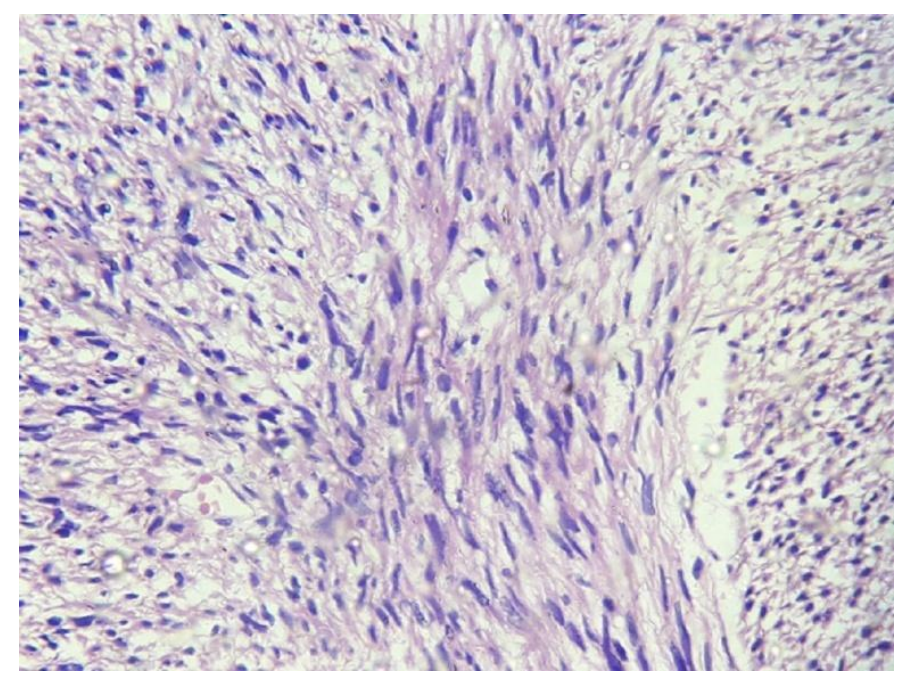

Figure 2: Biopsy from the bladder showing cellular spindle cell neoplasm composed of irregular fascicles (H and E, 400X).

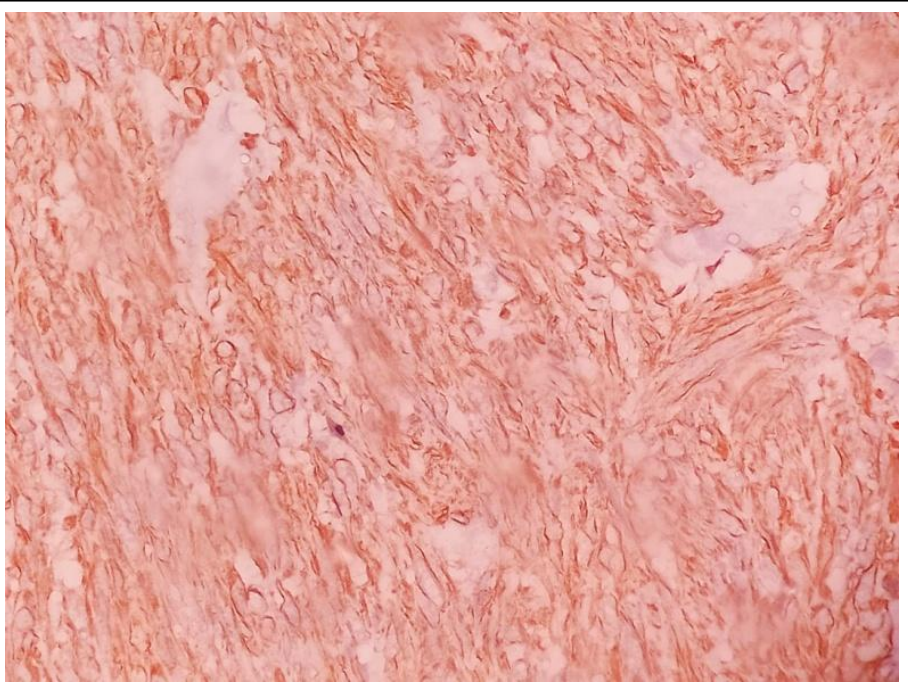

Figure 3: Tumor cells showing cytoplasmic positivity for SMA (400X)

\section{Discussion}

Leiomyosarcoma is a rare mesenchymal tumor arising from urinary bladder. More than 100 cases have been reported in literature. Gross hematuria is the most common presentation. ${ }^{3}$ This patient also presented with painless hematuria. Cyclophosphamide exposure, pelvic radiotherapy and retinoblastoma gene mutation were identified as probable risk factors for the development of leiomyosarcoma bladder. ${ }^{4}$ Tobacco use was not associated with increased occurrence of leiomyosarcoma. ${ }^{5}$ There was no identifiable risk factor for this patient.

Diagnosis is confirmed by cystoscopy and biopsy. Leiomyosarcoma is characterised by interlacing fascicles of spindle cells with nuclear atypia and mitosis. It should be differentiated from other spindle cell neoplasms like sarcomatoid carcinoma and inflammatory myofibroblastic tumor. On immunohistochemistry tumor cells show positivity for vimentin, smooth muscle actin (SMA) and desmin. Leiomyosarcomas are divided into low grade and high grade base on nuclear atypia and mitotic count. High grade leiomyosarcomas are associated with higher mortality compared to low grade sarcomas. ${ }^{6}$

Surgery is the main stay of treatment. High grade LMS should be treated with radical cystectomy and urinary diversion. Partial cystectomy can be considered in selected patients with low grade 
tumors. Negative surgical resection margins were associated with good recurrence free survival and overall survival in retrospective series. ${ }^{7}$ The role of adjuvant treatment is unclear. This patient was given adjuvant chemotherapy with

Adriamycin and ifosfamide considering the higher tumor grade. The patient is alive with no evidence of disease after one year of treatment. Adjuvant radiotherapy can be considered in patients with positive surgical margins. Metastatic diseases are treated by combination chemotherapy. The most common chemotherapeutic agents being Adriamycin, ifosfamide, cisplatin and docetaxel.

\section{Conclusion}

LMS is rare mesenchymal neoplasm arising from urinary bladder. Most of the cases are high grade. Radical surgery with negative surgical margins is the standard treatment for localized disease. The benefit of adjuvant treatment is not known.

\section{Sources of support: nil}

Previous presentations or publications: presented as a poster in AROICON 2019, Ahemadabad

\section{Conflict of interest: nil}

\section{References}

1. Dahm P, Gschwend JE. Malignant nonurothelial neoplasms of the urinary bladder: a review. EurUrol 2003;44:67281.

2. Slaoui H, Sanchez- Salas R, Validire P, Barret E, Rozet F, Galiano M, et al. Urinary bladder leiomyosarcoma: Primary surgical treatment. Urol Case Rep 2014;2:137- 8.

3. Rosser CJ, Slaton JW, Izawa JI, Levy LB, Dinney CP. Clinical presentation and outcome of high-grade urinary bladder leiomyosarcoma in adults. Urology 2003;61:1151-5.
4. Parekh DJ, Jung C, O'Conner J, et al. Leiomyosarcoma in urinary bladder after cyclophosphamide therapy for retinoblastoma and review of bladder sarcomas. Urology. 2002 Jul;60:164.

5. Labanaris AP, Zugor V, Meyer B, et al. Urinary bladder leiomyosarcoma in adults. Int Urol Nephrol. 2008;40:311e316.

6. Helen Zieschanga Rainer Kochb Manfred P. Wirtha Michael Froehner. Leiomyosarcoma of the Urinary Bladder in Adult Patients: A Systematic Review of the Literature and Meta-Analysis.

7. Spiess PE, Kassouf W, Steinberg JR, Tuziak $\mathrm{T}$ Hernandez M, Tibbs RF, Czerniak B, Kamat AM, Dinney CP, Grossman HB: Review of the M.D. Anderson experience in the treatmentof bladder sarcoma. UrolOncol 2007;25:3845. 